\title{
Tick vaccines and the control of tick-borne pathogens
}

\author{
Octavio Merino ${ }^{1}$, Pilar Alberdi ${ }^{1}$, José M. Pérez de la Lastra ${ }^{1}$ and José de la Fuente ${ }^{1,2 *}$ \\ 1 SaBio, Instituto de Investigación en Recursos Cinegéticos IREC-CSIC-UCLM-JCCM, Ciudad Real, Spain \\ 2 Department of Veterinary Pathobiology, Center for Veterinary Health Sciences, Oklahoma State University, Stillwater, OK, USA
}

Edited by:

Agustín Estrada-Peña, University of

Zaragoza, Spain

Reviewed by:

Christine Maritz-Olivier, Univeristy of

Pretoria, South Africa

Ana G. Domingos, Universidade

Nova de Lisboa, Portugal

*Correspondence:

José de la Fuente, Instituto de

Investigación en Recursos

Cinegéticos, Ronda de Toledo s/n,

13005 Ciudad Real, Spain

e-mail: jose_delafuente@yahoo.com
Ticks are obligate hematophagous ectoparasites that transmit a wide variety of pathogens to humans and animals. The incidence of tick-borne diseases has increased worldwide in both humans and domestic animals over the past years resulting in greater interest in the study of tick-host-pathogen interactions. Advances in vector and pathogen genomics and proteomics have moved forward our knowledge of the vector-pathogen interactions that take place during the colonization and transmission of arthropod-borne microbes. Tick-borne pathogens adapt from the vector to the mammalian host by differential gene expression thus modulating host processes. In recent years, studies have shown that targeting tick proteins by vaccination can not only reduce tick feeding and reproduction, but also the infection and transmission of pathogens from the tick to the vertebrate host. In this article, we review the tick-protective antigens that have been identified for the formulation of tick vaccines and the effect of these vaccines on the control of tick-borne pathogens.

Keywords: tick-borne pathogens, vaccine, transmission-blocking, tick, vector

\section{INTRODUCTION}

Ticks are of great medical and veterinary importance as they can transmit a wide variety of infectious agents (de la Fuente et al., 2008a). The family Ixodidae comprises hard ticks of the Amblyomma, Dermacentor, Rhipicephalus, and Ixodes spp. that not only inflict direct damage to their host but also rank second to mosquitoes as vectors of disease. The Ixodes ricinus species alone transmits viruses, bacteria, and protozoa that cause in humans tick-borne encephalitis, Lyme disease, and babesiosis, respectively (de la Fuente et al., 2008a). In cattle, anaplasmosis caused by Anaplasma spp., and babesiosis, caused by Babesia spp., are two of the most important diseases transmitted by Rhipicephalus spp. ticks (Merino et al., 2011a).

Vector-borne diseases are on the increase and new infectious agents are also emerging leading to significant public health concerns as potential zoonotic disease threats (Parola and Raoult, 2001; de la Fuente and Estrada-Peña, 2012). Amongst other factors, climate change itself can have an adverse effect on the distribution of ticks and tick-borne diseases. It is predicted that more than $50 \%$ of tick species of the genus Rhipicephalus (Boophilus) could expand its range in Africa, with more than $70 \%$ of this range expansion linked to economically important tick species such as $R$. appendiculatus, $R$. microplus, or $R$. decoloratus (Estrada-Peña et al., 2006; Olwoch et al., 2007).

The ultimate goal of arthropod vector vaccines is the control of vector infestations and vector-borne diseases (VBD). The effect of vector vaccines on VBD could be obtained by (a) reducing vector populations and thus the exposure of susceptible hosts to vectorborne pathogens, (b) reducing the arthropod vector capacity for pathogen transmission, and, preferably, (c) a combination of these factors.
Herein, we review recent advances in tick vaccine development focused on discovery and characterization of tick protective antigens that impact on pathogen infection and transmission. Identification of molecules essential for both tick survival and pathogen infection and transmission will likely contribute to the discovery of novel vaccine strategies for the simultaneous control of ticks and tick-borne pathogens (Figure 1).

\section{CONTROL METHODS FOR TICKS AND TICK-BORNE DISEASES}

A major component of integrated tick control has been the application of acaricides. However, their use has had limited efficacy in reducing tick infestations and is often accompanied by serious drawbacks, including the selection of acaricide-resistant ticks, environmental contamination and contamination of milk and meat products with drug residues (Graf et al., 2004; Ghosh et al., 2007).

An alternative host-targeted method involves the elimination of ticks from the host using baits impregnated with different compounds such as acaricides or antibiotics. Immature I. scapularis ticks were eliminated from mice using bait boxes impregnated with fipronil, therefore reducing the subsequent populations of nymphs and adults and thus reducing the proportion of ticks infected with the Lyme disease agent, Borrelia burgdorferi (Sonenshine et al., 2006). Field trials by Dolan et al. (2011) have revealed that infections rates with A. phagocytophilum and $B$. burgdorferi can be significantly reduced in both rodent reservoirs and ticks I. scapularis using antibiotic-treated baits. Thus this method can successfully reduce tick infestations and may also help to reduce pathogen transmission but can also contribute to the selection of acaricide and/or antibiotic resistant ticks.

Ecological approaches to control diseases involve intervention in the natural cycle of disease agents vaccinating wild reservoirs 


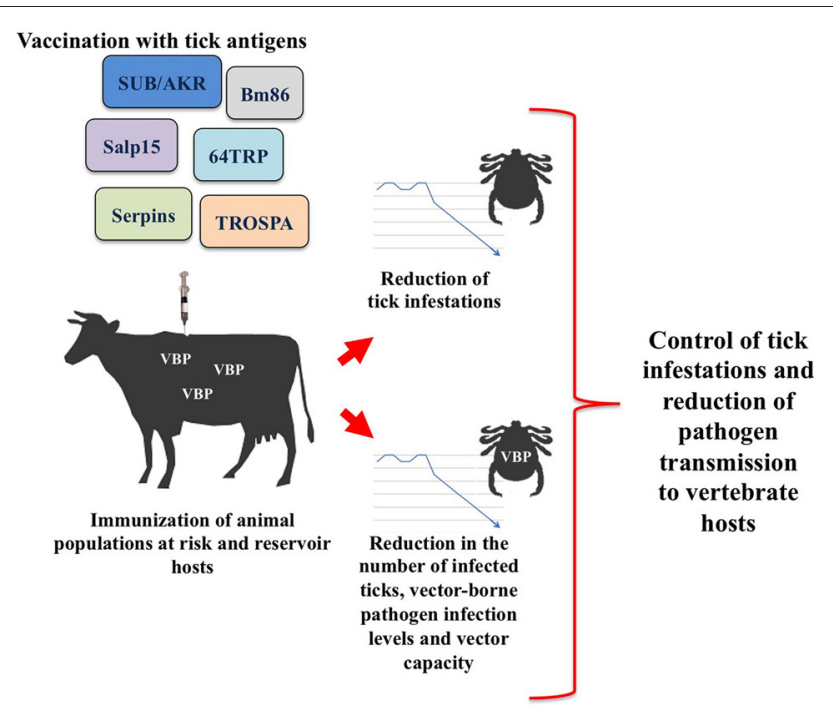

FIGURE 1 | Transmission blocking vaccines based on tick recombinant proteins aim to reduce vector infestations and the infection and transmission of vector-borne pathogens (VBP).

but the effects may be complex and hard to predict. For instance, Tsao et al. (2004) immunized white-footed mice, reservoir host for the Lyme disease agent, with a recombinant outer surface protein A (OspA). Even though vaccination significantly reduced the prevalence of $B$. burgdorferi in nymphal ticks, the results also indicated that non-mouse hosts played a larger than expected role in infection dynamics, suggesting the need to vaccinate additional hosts.

Entomopathogenic fungi, such as Metarhizium anisopliae and Beauveria bassiana, are active against a range of several economically important species of ticks under laboratory and field conditions, for example $R$. annulatus (Pirali-Kheirabadi et al., 2007), I. scapularis (Hornbostel et al., 2005), R. appendiculatus and $A$. variegatum (Kaaya et al., 1996). Despite the relative safety of this type of biocontrol method they haven't been successfully implemented as yet because of their environmental instability, and potential damage to non-target species.

Ticks can harbor a wide range of endosymbiotic bacteria including Rickettsia, Francisella, Coxiella, and Arsenophonus, amongst others (Alberdi et al., 2012). Tick control strategies could be devised based on interference with their endosymbionts for the control of these vectors and the pathogens they hold (Ghosh et al., 2007). For instance, Wolbachia pipientis when transfected into Aedes aegypti mosquitoes hinders the replication of Dengue and Chikungunya viruses (Iturbe-Ormaetxe et al., 2011).

Vaccination is an attractive alternative for the control of tick infestations and pathogen infections as it is a more environmentally friendly method. By targeting a common vector, several tick-borne diseases can be controlled simultaneously (Brossard, 1998; de la Fuente et al., 1998, 2007a,b, 2011; Rodríguez Valle et al., 2004; Almazán et al., 2005b). Since vectorborne pathogens exploit tick proteins to establish an infection, targeting the pathogen in the vector by blocking transmission is an innovative and promising method to control vector-borne infections (Lee and Opdebeeck, 1999; Havlíková et al., 2009). However, the selection of suitable antigens is a major constraint on vaccine development.

\section{FINDING CANDIDATE TICK PROTECTIVE ANTIGENS}

Candidate tick protective antigens have been identified using high throughput screening technologies allowing rapid, systematic and global antigen screening and providing a comprehensive approach for the selection of candidate vaccine antigens (Diatchenko et al., 1999; Almazán et al., 2003; Antunes et al., 2012). Other screening approaches include using RNA interference (RNAi) (de la Fuente et al., 2005, 2008b, 2010; Almazán et al., 2010; Kocan et al., 2011) and capillary feeding (Almazán et al., 2005a; Canales et al., 2009a; Gonsioroski et al., 2012; RodriguezValle et al., 2012). Using a functional genomics approach, Antunes et al. (2012) identified differentially expressed genes in B. bigemina-infected Riphicephalus ticks. TROSPA and serum amyloid A in particular significantly reduced bacterial infection levels in the ticks. Other methods such as protein arrays (Manzano-Román et al., 2012) and yeast surface display (Schuijt et al., 2011b) have also been proposed for the identification and characterization of antigens that elicit tick immunity.

The tick protective antigen, Subolesin, was discovered by expression library immunization and evaluation of expressed sequence tags (Almazán et al., 2003). Ghosh et al. (2008) employed strategic methods for the isolation of targeted molecules using affinity purification of proteins showing reactivity with immunoglobulins of animals previously immunized with different sources of tick antigens. Rachinsky et al. (2008) investigated the differences in protein expression in midgut tissue of uninfected and Babesia bovis-infected R. microplus ticks to establish a proteome database containing proteins involved in pathogen transmission. As pathogen neutralization occurs within the feeding vector, the development of a successful transmissionblocking vaccine requires that the antigen induce high and long-lasting circulating antibody titers in immunized hosts.

Nano/microparticle technologies can be applied toward the development of transmission-blocking vaccines that target antigens expressed only inside the vector. Although not yet used in ticks, experiments by Dinglasan et al. (2013) showed that a single inoculation and controlled release of mosquito antigen in mice, elicited long-lasting protective antibody titers against malaria sexual stages. Conserved carbohydrate targets have been identified in the midgut of arthropod species (Dinglasan et al., 2005) and are a promising tool for the elaboration of transmission blocking vaccines that control a wide range of arthropod vectors.

\section{SPECIFIC TICK ANTIGENS AND THEIR EFFECT ON PATHOGEN TRANSMISSION (SEE TABLE 1) BM86-BASED VACCINES}

Tick vaccines became commercially available in the early 1990's for the control of cattle tick infestations (Willadsen et al., 1995; Canales et al., 1997; de la Fuente et al., 1998, 2007b). TickGARD (in Australia) and Gavac (in Latin American countries) are both derived from $R$. microplus midgut membrane-bound recombinant protein BM86. The protective action of BM86-based vaccines in cattle is due to the positive correlation between 
Table 1 | Overview of tick protective antigens and their effect on the control of tick-borne pathogens.

\begin{tabular}{|c|c|c|c|c|c|}
\hline Vaccinated hosts $(\mathrm{N})^{\mathrm{a}}$ & $\begin{array}{l}\text { Recombinant } \\
\text { tick antigen }\end{array}$ & Vector $^{b}$ & Pathogenc & $\begin{array}{l}\text { Reduction in vector } \\
\text { infection }^{d}\end{array}$ & References \\
\hline Cattle $(>260,000)$ & Bm86 & R. microplus & Babesia sp. & $76 \%{ }^{e}$ & de la Fuente et al., 1998 \\
\hline Cattle $(>260,000)$ & Bm86 & R. microplus & Anaplasma sp. & No effect & de la Fuente et al., 1998 \\
\hline Cattle (5) & Ba86 & R. annulatus & Babesia sp. & $\mathrm{N} / \mathrm{D}$ & Canales et al., 2009a \\
\hline Cattle (5) & Ba86 & R. annulatus & Anaplasma sp. & $\mathrm{N} / \mathrm{D}$ & Canales et al., 2009a \\
\hline Rabbit (4) & $\mathrm{Bm95}$ & R. microplus & Babesia sp. & $\mathrm{N} / \mathrm{D}$ & Canales et al., 2009b \\
\hline Rabbit (4) & Bm95 & R. microplus & Anaplasma sp. & $\mathrm{N} / \mathrm{D}$ & Canales et al., 2009b \\
\hline Cattle (5) & HGAg & H. a. anatolicum & Theileria annulata & $10 \%$ & $\begin{array}{l}\text { Das et al., 2005; Ghosh } \\
\text { et al., 2008; }\end{array}$ \\
\hline Cattle (5) & Haa86 & H. a. anatolicum & Theileria annulata & $\begin{array}{l}3 \text { calves survived } \\
\text { lethal challenge }\end{array}$ & Jeyabal et al., 2010 \\
\hline Cattle (5) & $\mathrm{Bm91}$ & R. microplus & Babesia, & $\mathrm{N} / \mathrm{D}$ & Willadsen et al., 1996 \\
\hline Cattle (5) & $\mathrm{Bm91}$ & R. microplus & Anaplasma & $\mathrm{N} / \mathrm{D}$ & Willadsen et al., 1996 \\
\hline Mice (5) & SUB & I. scapularis & A. phagocytophilum & $33 \%$ & de la Fuente et al., 2006b \\
\hline Cattle (4) & SUB & R. microplus & A. marginale & $98 \%$ & Merino et al., 2011b \\
\hline Cattle (4) & SUB & R. microplus & B. bigemina & $99 \%$ & Merino et al., 2011b \\
\hline Mice (15) & SUB & I. scapularis & B. burgdorferi & $40 \%$ & Bensaci et al., 2012 \\
\hline Mice (10) & 64TPR & I. ricinus & TBEV & $52 \%$ & Labuda et al., 2006 \\
\hline Rabbits (2); Cattle (4) & RmFER2 & $\begin{array}{l}\text { l. ricinus, } R \text {. } \\
\text { microplus, } R \text {. } \\
\text { annulatus }\end{array}$ & $\begin{array}{l}\text { Anaplasma sp., } \\
\text { Babesia sp. }\end{array}$ & $\mathrm{N} / \mathrm{D}$ & Hajdusek et al., 2010 \\
\hline Mice (5) & Salp15 & I. scapularis & B. burgdorferi & $60 \%$ & Dai et al., 2009 \\
\hline Mice (5) & Salp25D & 1. scapularis & B. burgdorferi & Three-fold & Narasimhan et al., 2007 \\
\hline Cattle (5) & $\begin{array}{l}\text { RAS-3, RAS-4, } \\
\text { RIM36 coktail }\end{array}$ & R. appendiculatus & T. parva & $38 \%$ & Imamura et al., 2008 \\
\hline Mice (5) & TROSPA & I. scapularis & B. burgdorferi & $75 \%$ & Pal et al., 2004 \\
\hline Mice (5) & tHRF & 1. scapularis & B. burgdorferi & $\begin{array}{l}20-30 \% \text { mice fully } \\
\text { protected }\end{array}$ & Dai et al., 2010 \\
\hline Mice (3) & TSLPI & I. scapularis & B. burgdorferi & $30 \%$ & Schuijt et al., 2011a \\
\hline
\end{tabular}

${ }^{a} N$, number of individuals per group.

${ }^{b}$ Arthropod vector species in which vaccine was tested.

c Pathogen species in which the effect of vaccination was tested.

${ }^{d}$ Reduction in vector infection was determined with respect to the control group vaccinated with adjuvant/saline.

e Overall reduction in the incidence of dead animals caused by infections with Babesia sp. after vaccination.

Abbreviation: N/D, not determined.

antigen-specific antibodies and reduction of ticks infestations and fertility (Rodríguez et al., 1995; de la Fuente et al., 1998; Merino et al., 2011a). The mechanism by which BM86 immunization affects ticks involves antibody-antigen interaction that interferes with the still unknown BM86 biological function thus reducing the number, weight and reproductive capacity of engorging female ticks (de la Fuente et al., 1998, 1999). As a result, the prevalence of some tick-borne pathogens can indirectly be affected (de la Fuente et al., 2007b). Vaccine trials with BM86 resulted in a reduction in the incidence of babesiosis, as well as reduced tick infestations in vaccinated cattle herds, and these results were corroborated in extensive field trials (de la Fuente et al., 1998, 2007a; Rodríguez Valle et al., 2004). However, because A. marginale is also mechanically transmitted by blood-contaminated mouth parts of biting insects and fomites, BM86 antigen vaccination controlled the transmission of $A$. marginale only in regions where ticks are the main vectors (de la Fuente et al., 1998).
Despite the effectiveness of these commercial BM86-based vaccines for the control of cattle tick infestations, they show strain-to strain variation in efficacy and are effective against Rhipicephalus tick species mainly (de la Fuente and Kocan, 2003; Willadsen, 2006; de la Fuente et al., 2007a,b; Odongo et al., 2007) hence the need to develop improved vaccine formulations (Guerrero et al., 2012).

\section{BM86 ORTHOLOGS AND HOMOLOGS}

BA86 is a recombinant $R$. annulatus BM86 ortholog protein with over 90\% similarity to BM86 (Canales et al., 2008). Experimental trials in cattle proved the efficacy of recombinant BA86 for the control of $R$. annulatus and $R$. microplus infestations, showing that the efficacy of both BM86 and BA86 is higher against $R$. annulatus. These results suggested that physiological differences between $R$. microplus and $R$. annulatus and those encoded in the sequence of BM86 orthologs 
may be responsible for the differences in susceptibility of tick species to BM86 vaccines (Canales et al., 2009a; Jeyabal et al., 2010).

A BM86 ortholog of Hyalomma anatolicum anatolicum, HAA86, was cloned and expressed by Azhahianambi et al. (2009). Jeyabal et al. (2010) reported that vaccination of cattle with the recombinant HAA86 antigen did not only protect against homologous tick challenge but also reduced tick transmission of Theileria annulata, thus protecting the animals against lethal exposure.

The R. microplus BM95 glycoprotein is a BM86 homologue that protects cattle against infestations by South American cattle tick strains not protected by BM86 vaccination (Canales et al., 2009 b). Studies with BM95 have shown it protects against a broader range of tick strain infestations suggesting BM95 could be a more universal antigen against infestations by $R$. microplus strains from different geographical areas (García-García et al., 2000; de la Fuente and Kocan, 2003).

The number of new upcoming promising targets that can affect both tick infestations and pathogen transmission is rising. Nijhof et al. (2010) have recently identified a novel protein from metastriate ticks with structural similarities to BM86, named ATAQ after a part of its signature peptide. Although its function is unknown, ATAQ is expressed in both midguts and Malpighian tubules, while BM86 is expressed only in midguts. The vaccine efficacy of recombinant ATAQ proteins against tick infestations has not been evaluated but it may constitute a good vaccine candidate with an increased cross-protective effect against heterologous ticks compared to BM86-based vaccines because ATAQ proteins are more conserved.

\section{TICK SALIVARY PROTEINS}

Arthropod vectors induce immunosuppression in the host during feeding and secrete pathogen transmission-enhancing factors that counteract host rejection responses. For example, the Lyme disease agent $B$. burgdorferi exploits tick salivary proteins (B-cell inhibitory protein BIP and Salp15 from I. ricinus and I. scapularis, respectively) to facilitate transmission to the mammalian host (Anguita et al., 2002, 2003; Hannier et al., 2004; Ramamoorthi et al., 2005). During feeding, tick salivary glands secrete a large variety of pharmacologically active molecules with immunosuppresive properties that facilitate pathogen transmission and are potential candidates for anti-tick vaccines that limit infestations and interfere with tick-borne pathogen transmission (Valenzuela, 2002; Ribeiro and Francischetti, 2003; Nuttall et al., 2006; Titus et al., 2006; Nuttall, 2009).

64TRP is a $15 \mathrm{kDa}$ protein that resembles mammalian host skin proteins, identified in expression libraries as a putative tick cement protein involved in the attachment and feeding of $R$. appendiculatus (Trimnell et al., 2002; Havlíková et al., 2009). The protein derives from the cement cone that secures the tick's mouthparts in the host skin and, as a broad-spectrum vaccine antigen, is effective against adult and immature stages of several tick species, including $I$. ricinus (Trimnell et al., 2005). Recombinant forms of $R$. appendiculatus 64TRP induce potent humoral and delayed type hypersensitivity responses (Trimnell et al., 2002). In hamster, guinea pig and rabbit models this cement antigen acts as a dual-action vaccine by targeting the tick-feeding site (impairing attachment and feeding) and cross-reacting with "concealed" midgut antigens, resulting in death of engorged ticks (Trimnell et al., 2002, 2005; Havlíková et al., 2009). Histological and immunocytological studies have indicated that the key mode of action of 64TRP immunisation is the local cutaneous delayed type hypersensitivity response induced at the skin site of tick feeding (Labuda et al., 2006). Recent experiments have illustrated how vaccination with this antigen also affects tick vector capacity. Labuda et al. (2006) reported that vaccination of mice with 64TRPP antigen prevented transmission of tick-borne encephalitis virus (TBEV) by $I$. ricinus thus having a protective effect on pathogen transmission.

Salp15 is another secreted salivary protein with host immunosuppressive properties, inhibiting $\mathrm{CD} 4^{+} \mathrm{T}$-cell activation (Anguita et al., 2002), complement activity (Schuijt et al., 2008), and dendritic cell function (Hovius et al., 2008a). OspC is an outer surface protein produced by $B$. burgdorferi. When ticks take a blood meal, the spirochetes initiate its synthesis in the midguts of infected ticks. Salp15 physically binds to OspC on B. burgdorferi spirochetes surface during exit from the salivary glands, facilitating the survival of spirochetes, pathogen transmission and host infection (Ramamoorthi et al., 2005; Dai et al., 2009). Salp15-OspC interaction potentially conceals OspC from the host immune response protecting the spirochete (Ramamoorthi et al., 2005). Mice immunized with recombinant Salp15 and challenged with $B$. burgdorferi infected nymphs were significantly protected from infection (Dai et al., 2009). Antibodies directed against Salp15 may separate Salp15 away from OspC leaving it exposed to the immune responses, or, hypothetically, Salp15 antibodies could bind to Salp15-coated spirochetes and release the spirochetes more effectively to phagocytes (Dai et al., 2009). Immunization of murine hosts with a combination of Salp15 and OspA provide better protection from B. burgdorferi infection than either alone (Dai et al., 2009). Salp15 homologs have been identified in $I$. ricinus ticks, they also bind $B$. garinii and $B$. afzelii OspC to facilitate spirochete transmission (Hovius et al., 2008b).

Salp25D is expressed by I. scapularis salivary glands and midguts (Das et al., 2001) and has homology to peroxiredoxins antioxidants (Barr and Gedamu, 2003). Immunization of mice with rSalp25D reduces Borrelia acquisition by I. scapularis (Narasimhan et al., 2007) demonstrating it plays a critical role during tick feeding in the mammalian host, protecting the bacteria from reactive oxygen produced by neutrophils and facilitating Borrelia acquisition by ticks. Therefore it could be used to vaccinate reservoir hosts to interrupt the spirochete life cycle and reduce its prevalence in ticks in Lyme disease endemic areas. Interestingly, Salp25D does not influence transmission from the tick to the mammalian host (Narasimhan et al., 2007).

The tick histamine release factor (tHRF) from I. scapularis was characterized by Dai et al. (2010). tHRF is secreted in tick saliva, upregulated in $B$. burgdorferi-infected ticks and it appears to have a role in tick engorgement and efficient $B$. burgdorferi transmission (Dai et al., 2010). Silencing tHRF by RNAi 
significantly impaired tick feeding and decreased $B$. burgdorferi infection levels in mice. Actively immunized mice with recombinant tHRF, or passively transferring tHRF antiserum, also markedly reduced the efficiency of tick feeding and B. burgdorferi infection in mice. Blocking tHRF might offer a viable strategy to develop vaccines that block tick feeding and therefore transmission of tick-borne pathogens.

The I. scapularis salivary protein TSLPI (Tick Salivary Lectin Pathway Inhibitor) identified by Schuijt et al. (2011a) protects $B$. burgdorferi from direct killing by the host complement system. Silencing TSLPI mRNA significantly reduces Borrelia loads in nymphs and also impairs transmission to mice. TSLPI plays a significant role in both transmission and acquisition of Borrelia (Schuijt et al., 2011a) but immunization against rTSLPI does not completely block bacterial transmission from the tick to the host, suggesting the need for a combination of tick proteins in future tick antigen-based vaccines to prevent Lyme disease (Schuijt et al., 2011b).

\section{OTHER TICK PROTEINS}

Ferritins are iron-storage proteins that play a pivotal role in the homeostasis of iron during tick feeding. A common heavy chain type ferritin 2 (Kopacek et al., 2003), without functional orthologs in vertebrates, has been recently characterized as a gut-specific protein secreted into the tick hemolymph, where it acts as an iron transporter (Hajdusek et al., 2009). Ferritin 2 (RmFER2) knockdown by RNAi and vaccination with the recombinant protein resulted in reduction of feeding, oviposition and fertility in $I$. ricinus, $R$. microplus and $R$. annulatus (Hajdusek et al., 2009, 2010) thus highlighting its potential use as a future dual action tick and tick-borne diseases protective antigen candidate.

TROSPA is a tick receptor for B. burgdorferi OspA that has been identified in the tick midgut (Pal et al., 2004; Antunes et al., 2012). Tick-borne pathogens can adapt from the vector to the mammalian host by differential gene expression. For example, outer surface proteins OspA and OspB are produced when Lyme disease spirochetes enter and reside in ticks ( $\mathrm{Pal}$ and Fikrig, 2003) but they are downregulated during transmission to the host. Other genes that facilitate transmission from ticks and colonization of the host such as bba52 and OspC are upregulated. TROSPA expression is upregulated during B. burgdorferi infection and downregulated during tick engorgement. The receptor's physiological function is unknown but binding of OspA to TROSPA is essential for B. burgdorferi to colonize the tick gut, thus supporting bacterial infection in the vector ( $\mathrm{Pal}$ et al., 2004). B. burgdorferi infection enhances expression of specific tick genes such as TROSPA and salp15 that can be targeted to prevent the transmission of Borrelia spirochetes and other tick-borne microbes (Hovius et al., 2007). Blocking TROSPA with TROSPA antisera or via RNA interference (RNAi) reduces $B$. burgdorferi adherence to the gut of I. scapularis, and as a result reduces bacterial colonization of the vector and, potentially, pathogen transmission to the host (Pal et al., 2004). Bacterial OspA has been used as a Lyme disease vaccine that blocks pathogen transmission as anti-OspA antibodies destroy the spirochetes in the tick gut before transmission to the host occurs ( $\mathrm{Pal}$ et al., 2000). Studies by Tsao et al. (2001) suggested that vaccination of mice with OspA could reduce transmission of the bacteria to the tick vector regardless of whether the reservoir host was previously infected or not. A combination of OspA with TROSPA antigens may enhance vaccine protective efficacy against Lyme disease.

Serpins (serine protease inhibitors) are a large family of structurally related proteins found in a wide variety of organisms, including hematophagous arthropods. They are known to regulate many important functions such as blood coagulation, food digestion, inflammatory and immune responses (Mulenga et al., 2001) and therefore are attractive target antigens for tick vaccine development. Combining different serpins to vaccinate cattle results in a reduction of engorgement rates and increased mortality of Haemaphysalis and Rhipicephalus ticks (Imamura et al., 2005, 2006). Furthermore, immunization of cattle with a cocktail vaccine containing recombinant $R$. appendiculatus serpins RAS-3, RAS-4, and a $36 \mathrm{kDa}$ immune-dominant protein RIM36, reduces tick infestations and also has an effect on the tick mortality rate of Theileria parva-infected ticks by increasing it from 10.8 to $48.5 \%$ in the vaccinated group (Imamura et al., 2008). Infection of cattle with T. parva could not be prevented by the vaccine although the presence of the pathogen in peripheral blood was delayed by a couple of days indicating the vaccine also had an effect on pathogen transmission to the mammalian host.

Tick Subolesin (SUB), the ortholog of insect and vertebrate akirins (AKR) (de la Fuente et al., 2006a; Goto et al., 2008; Canales et al., 2009c; Galindo et al., 2009; Macqueen and Johnston, 2009; Mangold et al., 2009), was discovered as a tick protective antigen in I. scapularis (Almazán et al., 2003). Most vertebrates have two closely related AKR homologues, AKR1 and AKR2 (Goto et al., 2008). Only one SUB/AKR gene has been identified in insects and ticks, which is evolutionary and functionally related to mammalian AKR2 (de la Fuente et al., 2006a; Goto et al., 2008; Galindo et al., 2009; Macqueen and Johnston, 2009). SUB has a role in tick immunity and other molecular pathways and has been shown to protect against tick infestations and infection by vector-borne pathogen such as A. phagocytophilum, A. marginale, B. bigemina, and B. burgdorferi (de la Fuente et al., 2006b; Merino et al., 2011b; Bensaci et al., 2012). RNAi experiments have demonstrated that SUB knockdown affects the expression of genes involved in multiple cellular pathways (de la Fuente et al., 2006c, 2008c). It also has an effect on pathogen infection by reducing tick innate immunity that results in higher infection levels but also indirectly by affecting tick tissue structure and function and the expression of genes required for pathogen infection, therefore interfering with pathogen infection and multiplication (Zivkovic et al., 2010; de la Fuente et al., 2011) (Figure 2). Vaccines containing conserved SUB/AKR protective epitopes have been shown to protect against tick, mosquito and sand fly infestations, thus suggesting the possibility of developing universal vaccines for the control of arthropod vector infestations (Moreno-Cid et al., 2013). However, the effects of SUB/AKR vaccines on vector-borne viruses showed no effect on tick-borne encephalitis virus infection and transmission (Havlíková et al., 2013). 


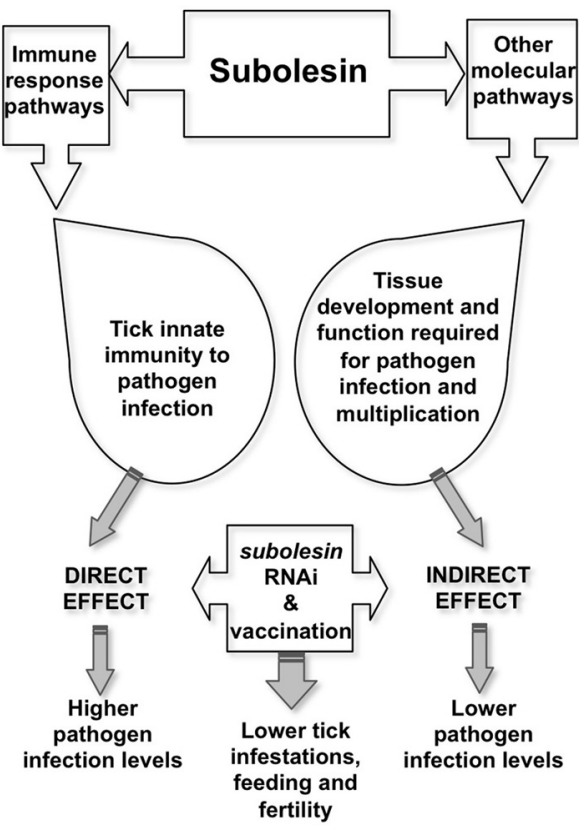

FIGURE 2 | Model for Subolesin role in pathogen infection. Targeting SUB by vaccination or RNAi reduces tick immunity, thereby increasing pathogen infection levels. However, lower pathogen infection levels may result from the effect on tissue structure and function and the expression of genes that are important for pathogen infection and multiplication. Both direct and indirect effects of targeting SUB results in lower tick infestations, feeding and fertility.

\section{CONCLUSIONS AND FUTURE DIRECTIONS}

This review has focused on studies showing the effects of tick antigens on the control of tick-borne pathogens by either decreasing the exposure of susceptible hosts to infected ticks (i.e., BM86) or by reducing tick vector capacity (i.e., TROSPA) (Kocan, 1995; de la Fuente and Kocan, 2003; Willadsen, 2006; de la Fuente et al., 2007a,b).

Tick-borne pathogens are maintained in a complex enzootic infection cycle involving ticks and vertebrate hosts (Wilson, 2002). Our understanding of the biology of vector-pathogen interactions, primarily involving model insects has advanced over the past decades. However, our knowledge of tick biology, especially the molecular interactions with the pathogens they maintain and transmit, and the mechanism by which the tick immune response influences invading pathogens, remains insufficient. The relative fitness of a pathogen within the vector can be a major determinant of pathogen prevalence within the vertebrate host population. For example, strains of the tick-borne rickettsia A. marginale differ markedly in their transmission efficiency (Ueti et al., 2009). These areas are understudied but important and warrant future investigation.

Transmission-blocking vaccines that interfere with specific aspects of tick physiology important for arthropod survival or development may prevent multiple infections that are often cotransmitted by a single tick species, an advantage over vaccines which only target particular pathogens. For example, immunization of hosts using SUB significantly inhibits tick infection with multiple pathogens such as $A$. marginale and B. bigemina (Merino et al., 2011b).

Progress in the development of transmission blocking vaccines has been slow. The limiting step in the development of vector vaccines has been the identification of new antigens that induce protective immune responses whilst preventing pathogen transmission (de la Fuente and Kocan, 2003). The number of proteins that may be of value as antigens has continued to increase quite rapidly over recent years but there have not been many reports of their actual assessment in vaccination trials (Willadsen, 2004; Guerrero et al., 2012). Very few antigens appear to be highly effective on their own suggesting the need for a multi-antigen or chimeric vaccine that incorporates critical tick and pathogen antigenic epitopes (Almazán et al., 2012; Parizi et al., 2012b; Moreno-Cid et al., 2013) to elicit synergistic anti-pathogen and anti-tick immune responses.

The selection of new vaccine antigens from the study of tick-pathogen interactions using systems biology requires the development of algorithm that allow the selection of the most effective targets to control tick infestations and pathogen transmission (de la Fuente, 2012).

Finally, identification of new protective antigens that are conserved across vector species, with similar structure and/or sequence motifs, may provide the opportunity to develop a universal and so more commercially viable vaccine for the control of multiple arthropod infestations and their associated pathogens (de la Fuente et al., 2011; Parizi et al., 2012a; Moreno-Cid et al., 2013).

\section{ACKNOWLEDGMENTS}

This research was supported by grants BFU2011-23896 and EU FP7 ANTIGONE project number 278976. Octavio Merino is an Early Stage Researcher supported by POSTICK ITN (postgraduate training network for capacity building to control ticks and tick-borne diseases) within the FP7-PEOPLE-ITN programme (EU Grant No. 238511).

\section{REFERENCES}

Alberdi, M. P., Dalby, M. J., RodriguezAndres, J., Fazakerley, J. K., Kohl, A., and Bell-Sakyi, L. (2012). Detection and identification of putative bacterial endosymbionts and endogenous viruses in tick cell lines. Ticks Tick Borne Dis. 3, 137-146. doi: 10.1016/j.ttbdis.2012.05.002

Almazán, C., Blas-Machado, U., Kocan, K. M., Yoshioka, J. H.,
Blouin, E. F., Mangold, A. J., et al. (2005a). Characterization of three Ixodes scapularis cDNAs protective against tick infestations. Vaccine 23, 4403-4416. doi: 10.1016/j.vaccine.2005.04.012

Almazán, C., Kocan, K. M., Blouin, E. F., and de la Fuente, J. (2005b). Vaccination with recombinant tick antigens for the control of Ixodes scapularis adult infestations.
Vaccine 23, 5294-5298. doi: 10.1016/j.vaccine.2005.08.004

Almazán, C., Kocan, K. M., Bergman, D. K., Garcia-Garcia, J. C., Blouin, E. F., and de la Fuente, J. (2003) Identification of protective antigens for the control of Ixodes scapularis infestations using cDNA expression library immunization. Vaccine 21, 1492-1501. doi: 10.1016/S0264410X(02)00683-7
Almazán, C., Lagunes, R., Villar, M., Canales, M., RosarioCruz, R., Jongejan, F. et al. (2010). Identification and characterization of Rhipicephalus (Boophilus) microplus candidate protective antigens for the control of cattle tick infestations. Parasitol. Res. 106, 471-479. doi: 10.1007/s00436009-1689-1 
Almazán, C., Moreno-Cantú, O., Moreno-Cid, J. A., Galindo, R. C., Canales, M., Villar, M., et al. (2012). Control of tick infestations in cattle vaccinated with bacterial membranes containing surface-exposed tick protective antigens. Vaccine, 30, 265-272. doi: 10.1016/j.vaccine.2011.10.102

Anguita, J., Hedrick, M. N., and Fikrig, E. (2003). Adaptation of Borrelia burgdorferi in the tick and the mammalian host. FEMS Microbiol. Rev. 27, 493-504. doi: 10.1016/S0168-6445(03)00036-6

Anguita, J., Ramamoorthi, N., Das, S., Thomas, V., Persinski, R., Conze, D., et al. (2002). Salp15, an Ixodes scapularis saliva protein, inhibits $\mathrm{CD} 4^{+} \mathrm{T}$ cell activation. Immunity 16, 849-859. doi: 10.1016/S10747613(02)00325-4

Antunes, S., Galindo, R. C., Almazán, C., Rudenko, N., Golovchenko, M., Grubhoffer, L., et al. (2012). Functional genomics studies of Rhipicephalus (Boophilus) annulatus ticks in response to infection with the cattle protozoan parasite, Babesia bigemina. Int. J. Parasitol. 42, 187-195. doi: 10.1016/j.ijpara.2011.12.003

Azhahianambi, P., de la Fuente, J., Suryanarayana, V. V., and Ghosh, S. (2009). Cloning, expression and immunoprotective efficacy of rHaa86, the homologue of the Bm86 tick vaccine antigen, from Hyalomma anatolicum anatolicum. Parasite Immunol. 31, 111-122. doi: 10.1111/j.1365-3024. 2008.01082.x

Barr, S. D., and Gedamu, L. (2003). Role of peroxidoxins in Leishmania chagasi survival. Evidence of an enzymatic defense against nitrosative stress. J. Biol. Chem. 278, 10816-10823. doi: 10.1074/jbc.M212990200

Bensaci, M., Bhattacharya, D., Clark, R., and Hu, L. T. (2012). Oral vaccination with vaccinia virus expressing the tick antigen subolesin inhibits tick feeding and transmission of Borrelia burgdorferi. Vaccine 30, 6040-6046. doi: 10.1016/j.vaccine.2012.07.053

Brossard, M. (1998). The use of vaccines and genetically resistant animals in tick control. Rev. Sci. Tech. 117, 188-199.

Canales, M., Almazán, C., Naranjo, V., Jongejan, F., and de la Fuente, J. (2009a). Vaccination with recombinant Boophilus annulatus Bm86 ortholog protein, Ba86, protects cattle against B. annulatus and B. microplus infestations. BMC Biotechnol. 9:29. doi: 10.1186/1472-6750-9-29

Canales, M., Labruna, M., Soares, J., Prudencio, C., and de la Fuente, J (2009b). Protective efficacy of bacterial membranes containing surfaceexposed BM95 antigenic peptides for the control of cattle tick infestations. Vaccine 27, 7244-7248. doi: 10.1016/j.vaccine.2009.09.123

Canales, M., Naranjo, V., Almazán, C., Molina, R., Tsuruta, S. A., Szabó, M. P. J., et al. (2009c). Conservation and immunogenicity of the mosquito ortholog of the tick protective antigen, subolesin. Parasitol. Res. 105, 97-111. doi: 10.1007/s00436-009-1368-2

Canales, M., Enríquez, A., Ramos, E., Cabrera, D., Dandie, H., Soto, A., et al. (1997). Large-scale production in Pichia pastoris of the recombinant vaccine $\mathrm{Gavac}^{\mathrm{TM}}$ against cattle tick. Vaccine 15, 414-422. doi: 10.1016/S0264410X(96)00192-2

Canales, M., Pérez de la Lastra, J. M., Naranjo, V., Nijhof, A. M., Hope, M., Jongejan, F., et al. (2008). Expression of recombinant Rhipicephalus (Boophilus) microplus, $R$. annulatus and $R$. decoloratus Bm86 orthologs as secreted proteins in Pichia pastoris. BMC Biotechnol. 8:14. doi: 10.1186/1472-6750-8-14

Dai, J., Narasimhan, S., Zhang, L., Liu, L., Wang, P., and Fikrig, E. (2010). Tick histamine release factor is critical for Ixodes scapularis engorgement and transmission of the Lyme disease agent. PLoS Pathog. 6:e1001205. doi: 10.1371/journal.ppat.1001205

Dai, J., Wang, P., Adusumilli, S., Booth, C. J., Narasimhan, S., Anguita, J., et al. (2009). Antibodies against a tick protein, Salp15, protect mice from the Lyme disease agent. Cell Host Microbe 6, 482-492.

Das, G., Ghosh, S., and Ray, D. D. (2005). Reduction of Theileria annulata infection in ticks fed on calves immunized with purified larval antigen of Hyalomma anatolicum anatolicum. Trop. Anim. Health Prod. 37, 345-361. doi: 10.1007/s11250-005-5080-7

Das, S., Banerjee, G., DePonte, K., Marcantonio, N., Kantor, F. S., and Fikrig, E. (2001). Salp25D, an Ixodes scapularis antioxidant, is 1 of 14 immunodominant antigens in engorged tick salivary glands. J. Infect. Dis. 184, 1056-1064. doi: $10.1086 / 323351$

de la Fuente, J. (2012). Vaccines for vector control: exciting possibilities for the future. Vet. J. 194, 139-140. doi: 10.1016/j.tvjl.2012.07.029

de la Fuente, J., Almazán, C., BlasMachado, U., Naranjo, V., Mangold, A. J., Blouin, E. F., et al. (2006a). The tick protective antigen, 4D8, is a conserved protein involved in modulation of tick blood ingestion and reproduction. Vaccine 24, 4082-4095. doi: 10.1016/j.vaccine.2006.02.046

de la Fuente, J., Almazán, C., Blouin, E. F., Naranjo, V., and Kocan, K. M. (2006b). Reduction of tick infections with Anaplasma marginale and A. phagocytophilum by targeting the tick protective antigen subolesin. Parasitol. Res. 100, 85-91. doi: 10.1007/s00436006-0244-6

de la Fuente, J., Almazán, C., Naranjo, V., Blouin, E. F., Meyer, J. M., and Kocan, K. M. (2006c). Autocidal control of ticks by silencing of a single gene by RNA interference. Biochem. Biophys. Res. Commun. 344, 332-338. doi: 10.1016/j.bbrc.2006.03.109

de la Fuente, J., Almazán, C., Blouin, E. F., Naranjo, V., and Kocan, K. M. (2005). RNA interference screening in ticks for identification of protective antigens. Parasitol. Res. 96, 137-141. doi: 10.1007/s00436-0051351-5

de la Fuente, J., Almazán, C., Canales, M., Pérez de la Lastra, J. M., Kocan, K. M., and Willadsen, P. (2007a). A ten-year review of commercial vaccine performance for control of tick infestations on cattle. An. Health Res. Rev. 8, 23-28.

de la Fuente, J., Kocan, K. M., and Blouin, E. F. (2007b). Tick vaccines and the transmission of tickborne pathogens. Vet. Res. Com 31(Suppl. 1), 85-90. doi: $10.1007 /$ s11259-007-0069-5

de la Fuente, J., and Estrada-Peña, A. (2012). Ticks and tick-borne pathogens on the rise. Ticks TickBorne Dis. 3, 115-116.

de la Fuente, J., Estrada-Peña, A., Venzal, J. M., Kocan, K. M., and Sonenshine, D. E. (2008a). Overview: ticks as vectors of pathogens that cause disease in humans and animals. Front. Biosci. 13, 6938-6946.

de la Fuente, J., Kocan, K. M., Almazán, C., and Blouin, E. F. (2008b). Targeting the tick-pathogen interface for novel control strategies. Front. Biosci. 13, 6947-6956. doi: $10.2741 / 3201$

de la Fuente, J., Maritz-Olivier, C., Naranjo, V., Ayoubi, P., Nijhof, A. M., Almazán, C., et al. (2008c).
Evidence of the role of tick subolesin in gene expression. BMC Genomics 9:372. doi: 10.1186/14712164-9-372

de la Fuente, J., and Kocan, K. M. (2003). Advances in the identification and characterization of protective antigens for development of recombinant vaccines against tick infestations. Exp. Rev. Vaccines 2, 583-593. doi: 10.1586/14760584.2.4.583

de la Fuente, J., Manzano-Román, R., Naranjo, V., Kocan, K. M., Zivkovic, Z., Blouin, E. F., et al. (2010). Identification of protective antigens by RNA interference for control of the lone star tick, Amblyomma americanum. Vaccine 28, 1786-1795. doi: 10.1016/j.vaccine.2009.12.007

de la Fuente, J., Moreno-Cid, J. A., Canales, M., Villar, M., Pérez de la Lastra, J. M., Kocan, K. M., et al. (2011). Targeting arthropod subolesin/akirin for the development of a universal vaccine for control of vector infestations and pathogen transmission. Vet. Parasitol. 181, 17-22. doi: 10.1016/j.vetpar.2011.04.018

de la Fuente, J., Rodriguez, M., Montero, C., Redondo, M. Garcia-Garcia, J. C., Mendez, L., et al. (1999). Vaccination against ticks (Boophilus spp.): the experience with the Bm86-based vaccine Gavac. Genet. Anal. 15, 143-148. doi: 10.1016/S1050-3862(99)00018-2

de la Fuente, J., Rodriguez, M., Redondo, M., Montero, C., García-García, J. C., Méndez, L., et al. (1998). Field studies and cost-effectiveness analysis of vaccination with Gavac $^{\mathrm{TM}}$ against the cattle tick Boophilus microplus. Vaccine 16, 366-373. doi: 10.1016/S0264-410X(97)00208-9

Diatchenko, L., Lukyanov, S., Lau, Y. F., and Siebert, P. D. (1999). Suppression subtractive hybridization: a versatile method for identifying differentially expressed genes. Methods Enzymol. 303, 349-380. doi: 10.1016/S00766879(99)03022-0

Dinglasan, R. R., Armistead, J. S., Nyland, J. F., Jiang, X., and Mao, H. Q. (2013). Singledose microparticle delivery of a malaria transmission- blocking vaccine elicits a long-lasting functional antibody response. Curr. Mol. Med. 13, 479-487. doi: 10.2174/1566524011313040002

Dinglasan, R. R., Valenzuela, J. G., and Azad, A. F. (2005). Sugar 
epitopes as potential universal disease transmission blocking targets. Insect Biochem. Mol. Biol. 35, 1-10. doi: 10.1016/j.ibmb.2004. 09.005

Dolan, M. C., Schulze, T. L., Jordan, R. A., Dietrich, G., Schulze, C. J., Hojgaard, A., et al. (2011). Elimination of Borrelia burgdorferi and Anaplasma phagocytophilum in rodent reservoirs and Ixodes scapularis ticks using a doxycycline hyclate-laden bait. Am. J. Trop. Med. Hyg. 85, 1114-1120. doi: 10.4269/ajtmh.2011.11-0292

Estrada-Peña, A., Bouattour, A., Camicas, J. L., Guglielmone, A., Horak, I., Jongejan, F., et al. (2006). The known distribution and ecological preferences of the tick subgenus Boophilus (Acari: Ixodidae) in Africa and Latin America. Exp. Appl. Acarol. 38, 219-235.

Galindo, R. C., Doncel-Pérez, E., Zivkovic, Z., Naranjo, V., Gortazar, C., Mangold, A. J., et al. (2009). Tick subolesin is an ortholog of the akirins described in insects and vertebrates. Dev. Comp. Immunol. 33, 612-617. doi: 10.1016/j.dci.2008.11.002

García-García, J. C., Montero, C., Redondo, M., Vargas, M., Canales, M., Boué, O., et al. (2000). Control of ticks resistant to immunization with Bm86 in cattle vaccinated with the recombinant antigen Bm95 isolated from the cattle tick, Boophilus microplus. Vaccine 18, 2275-2287. doi: 10.1016/S0264410X(99)00548-4

Ghosh, S., Azhahianambi, P., and Yadav, M. P. (2007). Upcoming and future strategies of tick control: a review. J. Vector Borne Dis. 44, 79-89.

Ghosh, S., Ray, D. D., Vanlahmuaka, Das, G., Singh, N. K., Sharma, J. K., and Azhahianambi, P. (2008). Progress in development of vaccine against Hyalomma anatolicum anatolicum-Indian scenario. Vaccine 26, G40-G47. doi: 10.1016/j.vaccine.2008.09.067

Gonsioroski, A. V., Bezerra, I. A., Utiumi, K. U., Driemeier, D., Farias, S. E., da Silva Vaz, I. Jr., et al. (2012). Anti-tick monoclonal antibody applied by artificial capillary feeding in Rhipicephalus (Boophilus) microplus females. Exp. Parasitol. 130, 359-363. doi: 10.1016/j.exppara. 2012.02 .006

Goto, A., Matsushita, K., Gesellchen, V., El Chamy, L., Kuttenkeuler, D., Takeuchi, O., et al. (2008).
Akirins are highly conserved nuclear proteins required for NF-kappaB-dependent gene expression in drosophila and mice. Nat. Immunol. 9, 97-104. doi: 10.1038/ni1543

Graf, J. F., Gogolewski, R., Leach-Bing, N., Sabatini, G. A., Molento, M. B., Bordin, E. L., et al. (2004). Tick control: an industry point of view. Parasitol. 129, S427-S442. doi: 10.1017/ S0031182004006079

Guerrero, F. D., Miller, R. J., and Pérez de León, A. A. (2012). Cattle tick vaccines: many candidate antigens, but will a commercially viable product emerge? Int. J. Parasitol. 42, 421-427. doi: 10.1016/j.ijpara.2012.04.003

Hajdusek, O., Almazán, C., Loosova, G., Villar, M., Canales, M., Grubhoffer, L., et al. (2010). Characterization of ferritin 2 for the control of tick infestations. Vaccine 28, 2993-2998. doi: 10.1016/j.vaccine.2010.02.008

Hajdusek, O., Sojka, D., Kopacek, P., Buresova, V., Franta, Z., Sauman, I., et al. (2009). Knockdown of proteins involved in iron metabolism limits tick reproduction and development. Proc. Natl. Acad. Sci. U.S.A. 106, 1033-1038. doi: 10.1073/pnas.0807961106

Hannier, S., Liversidge, J., Sternberg, J. M., and Bowman, A. S. (2004). Characterization of the Bcell inhibitory protein factor in Ixodes ricinus tick saliva: a potential role in enhanced Borrelia burgdorferi transmission. Immunology 113, 401-408. doi: 10.1111/j.1365-2567.2004.01975.x

Havlíková, S., Lièková, M., Ayllón, N., Roller, L., Kazimírová, M., Slovák, M., et al. (2013). Immunization with recombinant subolesin does not reduce tick infection with tickborne encephalitis virus nor protect mice against disease. Vaccine 31 , 1582-1589. doi: 10.1016/j.vaccine. 2013.01.017

Havlíková, S., Roller, L., Koèi, J., Trimnell, A. R., Kazimírová, M., Klempa, B., et al. (2009). Functional role of $64 \mathrm{P}$, the candidate transmission-blocking vaccine antigen from the tick, Rhipicephalus appendiculatus. Int. J. Parasitol. 39 1485-1494. doi: 10.1016/j.ijpara. 2009.05.005

Hornbostel, V. L., Ostfeld, R. S., and Benjamin, M. A. (2005). Effectiveness of Metarhizium anisopliae (Deuteromycetes) against Ixodes scapularis (Acari: Ixodidae) engorging on Peromnyscus leucopus. J. Vector Ecol. 30, 91-101.

Hovius, J. W., De Jong, M. A., Den Dunnen, J., Litjens, M., Fikrig, E., Van Der Poll, T., et al. (2008a). Salp15 binding to DC-SIGN inhibits cytokine expression by impairing both nucleosome remodeling and mRNA stabilization. PloS Pathog. 4:e31. doi 10.1371/journal.ppat.0040031

Hovius, J. W., Schuijt, T. J., De Groot, K. A., Roelofs, J. J., Oei, G. A., Marquart, J. A., et al. (2008b). Preferential protection of Borrelia burgdorferi sensu stricto by a Salp 15 homologue in Ixodes ricinus saliva. J. Infect. Dis. 198, 1189-1197. doi: 10.1086/591917

Hovius, J. W., van Dam, A. P., and Fikrig, E. (2007). Tickhost-pathogen interactions in Lyme borreliosis. Trends Parasitol. 23, 434-438. doi 10.1016/j.pt.2007.07.001

Imamura, S., da Silva Vaz, I., Sugino, M., Ohashi, K., and Onuma, M. (2005). A serine protease inhibitor (serpin) from Haemaphysalis longicornis as an anti-tick vaccine. Vaccine 23 , 1301-1311. doi: 10.1016/j.vaccine. 2004.08.041

Imamura, S., Konnai, S., Vaz Ida, S., Yamada, S., Nakajima, C., Ito, Y., et al. (2008). Effects of anti-tick cocktail vaccine against Rhipicephalus appendiculatus. Jpn. J. Vet. Res. 56, 85-98.

Imamura, S., Namangala, B., Tajima, T., Tembo, M. E., Yasuda, J., Ohashi, K., et al. (2006). Two serine protease inhibitors (serpins) that induce a bovine protective immune response against Rhipicephalus appendiculatus ticks. Vaccine 24 2230-2237. doi: 10.1016/j.vaccine. 2005.10.055

Iturbe-Ormaetxe, I., Walker, T., and O'Neill, S. L. (2011). Wolbachia and the biological control of mosquitoborne disease. EMBO Rep. 12, 508-518.

Jeyabal, L., Azhahianambi, P., Susitha, K., Ray, D. D., Chaudhuri, P. Vanlahmuaka, et al. (2010). Efficacy of rHaa86, an orthologue of Bm86, against challenge infestations of Hyalomma anatolicum anatolicum. Transbound. Emerg. Dis. 57, 96-102. doi: 10.1111/j.18651682.2010.01107.x

Kaaya, G. P., Mwangi, E. N., and Ouna, E. A. (1996). Prospects for biological control of livestock ticks, Rhipicephalus appendiculatus and Amblyomma variegatum, using the entomogenous fungi Beauveria bassiana and Metarhizium anisopliae. J. Invertebr. Pathol. 67, 15-20. doi: 10.1006/jipa.1996.0003

Kocan, K. M. (1995). Targeting ticks for control of selected hemoparasitic diseases of cattle. Vet. Parasitol. 57, 121-151. doi: 10.1016/03044017(94)03116-E

Kocan, K. M., Blouin, E., and de la Fuente, J., (2011). RNA interference in ticks. J. Vis. Exp. 47:e2474. doi: 10.3791/2474. http:// www.jove.com/details.stp?id=2474

Kopacek, P., Zdychova, J., Yoshiga, T., Weise, C., Rudenko, N., and Law, J. H. (2003). Molecular cloning, expression and isolation of ferritins from two tick species-Ornithodoros moubata and Ixodes ricinus. Insect. Biochem. Mol. Biol. 33, 103-113. doi: 10.1016/S09651748(02)00181-9

Labuda, M., Trimnell, A. R., Licková, M., Kazimírová, M., Davies, G. M., Lissina, O., et al. (2006). An antivector vaccine protects against a lethal vector-borne pathogen. PLoS Pathogens 2:e27. doi: 10.1371/ journal.ppat.0020027

Lee, R., and Opdebeeck, J. P. (1999). Arthropod vaccines. Infect. Dis. Clin. North Am. 13, 209-226. doi: 10.1016/S0891-5520(05)70051-9

Macqueen, D. J., and Johnston, I. A. (2009). Evolution of the multifaceted eukaryotic akirin gene family. BMC Evol. Biol. 9:34. doi: 10.1186/1471-2148-9-34

Mangold, A. J., Galindo, R. C., and de la Fuente, J. (2009). Response to the commentary of D. Macqueen on: Galindo, R. C., Doncel-Pérez, E., Zivkovic, Z., Naranjo, V., Gortazar, C., Mangold, A. J, et al. (2009). Tick subolesin is an ortholog of the akirins described in insects and vertebrates [Dev. Comp. Immunol. 33: 612-617]. Dev. Comp. Immunol. 33, 878-879. doi: 10.1016/j.dci.2009.02.010

Manzano-Román, R., Díaz-Martín, V., González-González, M., Matarraz, S., Francisco Álvarez-Prado, A., et al. (2012). Self-assembled protein arrays from an Ornithodoros moubata salivary gland expression library. J. Proteome Res. 11, 5972-5982.

Merino, O., Almazán, C., Canales, M., Villar, M., Moreno-Cid, J. A., Estrada-Peña, A., et al (2011a). Control of Rhipicephalus (Boophilus) microplus infestations by the combination of subolesin vaccination and tick autocidal control after subolesin gene knockdown in ticks fed on cattle. Vaccine 29, 2248-2254. 
Merino, O., Almazán, C., Canales, M., Villar, M., Moreno-Cid, J. A., Galindo, R. C., et al. (2011b). Targeting the tick protective antigen subolesin reduces vector infestations and pathogen infection by Anaplasma marginale and Babesia bigemina. Vaccine 29, 8575-8579. doi: 10.1016/j.vaccine. 2011.09.023

Moreno-Cid, J. A., Pérez de la Lastra, J. M., Villar, M., Jiménez, M., Pinal, R., Estrada-Peña, A., et al. (2013). Control of multiple arthropod vector infestations with subolesin/akirin vaccines. Vaccine 31, 1187-1196. doi: 10.1016/j.vaccine. 2012.12.073

Mulenga, A., Sugino, M., Nakajima, M., Sugimoto, C., and Onuma, M. (2001). Tick-encoded serine proteinase inhibitors (serpins); potential target antigens for tick vaccine development. J. Vet. Med. Sci. 63, 1063-1069. doi: 10.1292/jvms.63.1063

Narasimhan, S., Sukumaran, B., Bozdogan, U., Thomas, V., Liang, X., DePonte, K., et al. (2007). A tick antioxidant facilitates the Lyme disease agent's successful migration from the mammalian host to the arthropod vector. Cell Host Microbe. 12, 7-18. doi: 10.1016/j.chom.2007.06.001

Nijhof, A. M., Balk, J. A., Postigo, M., Rhebergen, A. M., Taoufik, A., and Jongejan, F. (2010). Bm86 homologues and novel ATAQ proteins with multiple epidermal growth factor (EGF)-like domains from hard and soft ticks. Int. J. Parasitol. 40, 1587-1597. doi: 10.1016/j.ijpara. 2010.06.003

Nuttall, P. A. (2009). Molecular characterization of tick-virus interactions. Front. Biosci. 14, 2466-2483. doi: $10.2741 / 3390$

Nuttall, P. A., Trimnell, A. R., Kazimirova, M., and Labuda, M. (2006). Exposed and concealed antigens as vaccine targets for controlling ticks and tick-borne diseases. Parasite Immunol. 28, 155-163. doi: 10.1111/j.1365-3024. 2006.00806. $\mathrm{x}$

Odongo, D., Kamau, L., Skilton, R., Mwaura, S., Nitsch, C., Musoke, A., et al. (2007). Vaccination of cattle with TickGARD induces cross-reactive antibodies binding to conserved linear peptides of Bm86 homologues in Boophilus decoloratus. Vaccine 25, 1287-1296. doi: 10.1016/j.vaccine. 2006.09.085

Olwoch, J. M., Van Jaarsveld, A. S., Scholtz, C. H., and Horak,
I. G. (2007). Climate change and the genus Rhipicephalus (Acari: Ixodidae) in Africa. Onderstepoort J. Vet. Res. 74, 45-72. doi: 10.4102/ojvr.v74i1.139

Pal, U., de Silva, A. M., Montgomery, R. R., Fish, D., Anguita, J., Anderson, J. F., et al. (2000). Attachment of Borrelia burgdorferi within Ixodes scapularis mediated by outer surface protein A. J. Clin. Invest. 106, 561-569. doi: 10.1172/ JCI9427

Pal, U., and Fikrig, E. (2003). Adaptation of Borrelia burgdorferi in the vector and vertebrate host. Microbes Infect. 5, 659-666. doi: 10.1016/S1286-4579 (03)00097-2

Pal, U., Li, X., Wang, T., Montgomery, R. R., Ramamoorthi, N., Desilva, A. M., et al. (2004). TROSPA, an Ixodes scapularis receptor for Borrelia burgdorferi. Cell 119, 457-468. doi: 10.1016/j.cell. 2004.10.027

Parizi, L. F., Githaka, N. W., Logullo, C., Konnai, S., Masuda, A., Ohashi, K., et al. (2012a). The quest for a universal vaccine against ticks: cross-immunity insights. Vet. J. 194, 158-165. doi: 10.1016/j.tvjl.2012.05.023

Parizi, L. F., Reck, J., Oldiges, D. P., Guizzo, M. G., Seixas, A., Logullo, C., et al. (2012b). Multiantigenic vaccine against the cattle tick Rhipicephalus (Boophilus) microplus: a field evaluation. Vaccine 30, 6912-6917. doi: 10.1016/j.vaccine.2012.08.078

Parola, P., and Raoult, D. (2001). Tick-borne bacterial diseases emerging in Europe. Clin. Microbiol. Infect. 7, 80-83. doi: 10.1046/j.1469-0691.2001.00200.x

Pirali-Kheirabadi, K., Haddadzadeh, H., Razzaghi-Abyaneh, M., Bokaie, S., Zare, R., Ghazavi, M., et al. (2007). Biological control of Rhipicephalus (Boophilus) annulatus by different strains of Metarhizium anisopliae, Beauveria bassiana and Lecanicillium psalliotae fungi. Parasitol. Res. 100, 1297-1302. doi: 10.1007/s00436-006-0410-x

Rachinsky, A., Guerrero, F. D., and Scoles, G. A. (2008). Proteomic profiling of Rhipicephalus (Boophilus) microplus midgut responses to infection with Babesia bovis. Vet. Parasitol. 152, 294-313. doi: 10.1016/j.vetpar.2007.12.027

Ramamoorthi, N., Narasimhan, S., Pal, U., Bao, F., Yang, X. F., Fish, D., et al. (2005). The Lyme disease agent exploits a tick protein to infect the mammalian host.
Nature 436, 573-577. doi: 10.1038/ nature 03812

Ribeiro, J. M., and Francischetti, I. M. (2003). Role of arthropod saliva in blood feeding: sialome and post-sialome perspectives. Ann. Rev. Entomol. 48, 73-88. doi: 10.1146/annurev. ento.48.060402.102812

Rodríguez, M., Massard, C. L., da Fonseca, A. H., Ramos, N. F., Machado, H., Labarta, V., et al. (1995). Effect of vaccination with a recombinant $\mathrm{Bm} 86$ antigen preparation on natural infestations of Boophilus microplus in grazing dairy and beef pure and crossbred cattle in Brazil. Vaccine 13, 1804-1808. doi: 10.1016/0264410X(95)00119-L

Rodríguez Valle, M., Méndez, L., Valdez, M., Redondo, M., Espinosa, C. M., Vargas, M., et al. (2004). Integrated control of Boophilus microplus ticks in Cuba based on vaccination with the anti-tick vaccine Gavac. Exp. Appl. Acarol. 34, 375-382.

Rodriguez-Valle, M., Vance, M. Moolhuijzen, P. M., Tao, X., and Lew-Tabor, A. E. (2012). Differential recognition by tick-resistant cattle of the recombinantly expressed Rhipicephalus microplus serine protease inhibitor3 (RMS-3). Ticks Tick Borne Dis. 3 , 159-169. doi: 10.1016/j.ttbdis. 2012.03.002

Schuijt, T. J., Coumou, J., Narasimhan, S., Dai, J., Deponte, K., Wouters, D., et al. (2011a). A tick mannosebinding lectin inhibitor interferes with the vertebrate complement cascade to enhance transmission of the lyme disease agent. Cell Host. Microbe. 10, 136-46. doi 10.1016/j.chom.2011.06.010

Schuijt, T. J., Narasimhan, S., Daffre, S., Deponte, K., Hovius, J. W., Veer, C. V., et al. (2011b). Identification and characterization of Ixodes scapularis antigens that elicit tick immunity using yeast surface display. PLoS ONE 6:e15926. doi: 10.1371/journal.pone.0015926

Schuijt, T. J., Hovius, J. W., Van Burgel, N. D., Ramamoorthi, N., Fikrig, E., and Van Dam, A. P. (2008). The tick salivary protein Salp15 inhibits the killing of serum-sensitive Borrelia burgdorferi sensu lato isolates. Infect. Immun. 76, 2888-2894. doi: 10.1128/IAI 00232-08

Sonenshine, D. E., Kocan, K. M., and de la Fuente, J. (2006). Tick control: further thoughts on a research agenda. Trends
Parasitol. 22, 550-551. doi: 10.1016/j.pt.2006.09.003

Titus, R. G., Bishop, J. V., and Mejia, J. S. (2006). The immunomodulatory factors of arthropod saliva and the potential for these factors to serve as vaccine targets to prevent pathogen transmission. Parasite Immunol. 28, 131-141. doi: 10.1111/j.1365-3024.2006.00807.x

Trimnell, A. R., Davies, G. M., Lissina, O., Hails, R. S., and Nuttall, P. A. (2005). A crossreactive tick cement antigen is a candidate broad-spectrum tick vaccine. Vaccine 23, 4329-4341. doi: 10.1016/j.vaccine.2005.03.041

Trimnell, A. R., Hails, R. S., and Nuttall, P. A. (2002). Dual action ectoparasite vaccine targeting "exposed" and "concealed" antigens. Vaccine 20, 3560-3568. doi: 10.1016/S0264410X(02)00334-

Tsao, J., Barbour, A. G., Luke, C. J., Fikrig, E., and Fish, D. (2001). OspA immunization decreases transmission of Borrelia burgdorferi spirochetes from infected Peromyscus leucopus mice to larval Ixodes scapularis ticks. Vector Borne Zoonotic Dis. 1, 65-74 doi: 10.1089/153036601750137705

Tsao, J. I., Wootton, J. T., Bunikis, J., Luna, M. G., Fish, D., and Barbour, A. G. (2004). An ecological approach to preventing human infection: vaccinating wild mouse reservoirs intervenes in the Lyme disease cycle. Proc. Natl. Acad. Sci. U.S.A. 101, 18159-18164 doi: 10.1073/pnas.0405763102

Ueti, M. W., Knowles, D. P., Davitt, C. M., Scoles, G. A., Baszler, T. V., and Palmer, G. H. (2009). Quantitative differences in salivary pathogen load during tick transmission underlie strain-specific variation in transmission efficiency of Anaplasma marginale. Infect. Immun. 77, 70-75. doi: 10.1128/IAI.01164-08

Valenzuela, J. G. (2002). Highthroughput approaches to study salivary proteins and genes from vectors of disease. Insect. Biochem. Mol. Biol. 32, 1199-1209. doi 10.1016/S0965-1748(02)00083-8

Willadsen, P. (2004). Anti-tick vaccines. Parasitology 129, S367-S387. doi: $10.1017 /$ S0031182003004657

Willadsen, P. (2006). Tick control: thoughts on a research agenda. Vet. Parasitol. 138, 161-168. doi 10.1016/j.vetpar.2006.01.050

Willadsen, P., Bird, P., Cobon, G. S., and Hungerford, J. (1995). Commercialization of a recombinant vaccine against Boophilus microplus. Parasitology 110, 
S43-S50. doi: 10.1017/S003118200 0001487

Willadsen, P., Smith, D., Cobon, G., and McKenna, R. V. (1996). Comparative vaccination of cattle against Boophilus microplus with recombinant antigen $\mathrm{Bm} 86$ alone or in combination with recombinant Bm91. Parasite Immunol. 18, 241-246. doi: 10.1046/j.1365-3024.1996.d01-90.x

Wilson, M. E. (2002). Prevention of tick-borne diseases. Med. Clin.
North Am. 86, 219-238. doi: 10.1016/S0025-7125(03)00084-1

Zivkovic, Z., Torina, A., Mitra, R., Alongi, A., Scimeca, S., Kocan, K. M., et al. (2010). Subolesin expression in response to pathogen infection in ticks. $B M C$ Immunol. 11:7. doi: 10.1186/14712172-11-7

Conflict of Interest Statement: The authors declare that the research was conducted in the absence of any commercial or financial relationships that could be construed as a potential conflict of interest.

Received: 30 April 2013; accepted: 21 June 2013; published online: 09 July 2013.

Citation: Merino O, Alberdi P, Pérez de la Lastra JM and de la Fuente $J$ (2013) Tick vaccines and the control of tick-borne pathogens. Front. Cell.
Infect. Microbiol. 3:30. doi: 10.3389/ fcimb.2013.00030

Copyright (c) 2013 Merino, Alberdi, Pérez de la Lastra and de la Fuente. This is an open-access article distributed under the terms of the Creative Commons Attribution License, which permits use, distribution and reproduction in other forums, provided the original authors and source are credited and subject to any copyright notices concerning any third-party graphics etc. 